\title{
O processo de consolidação e expansão do Campus da Universidade Federal de Juiz de Fora: reflexões sobre o REUNI e seus impactos nas transformações da paisagem do campus e seu entorno imediato
}

\author{
The consolidation and expansion process of the Federal \\ University of Juiz de Fora Campus: reflections on REUNI and its \\ impacts on the transformations of the campus landscape and \\ its immediate surroundings
}

Ana Clara Carvalho Tourinho [a] [D], Sabrina Andrade Barbosa [a,b] [D], Cézar Henrique Barra Rocha [a] [D, Tamires Oliveira Prado[a] [D, Klaus Chaves Alberto[a] [D

Como citar: Tourinho, A. C. C., Barbosa, S. A., Rocha, C. H. B., Prado, T. O. \& Alberto, K. C. (2021). 0 processo de consolidação e expansão do Campus da Universidade Federal de Juiz de Fora: reflexões sobre o REUNI e seus impactos nas transformações da paisagem do campus e seu entorno imediato. urbe. Revista Brasileira de Gestão Urbana, v. 13, e20200069. https://doi.org/10.1590/2175-3369.013.e20200069

\section{Resumo}

Esse trabalho tem como objetivo analisar como o campus da Universidade Federal de Juiz de Fora (UFJF) se configura como um agente de estruturação na dinâmica da cidade a partir do estudo das transformações no uso do solo nos limites do campus e em seu entorno imediato. Para isso, foram elaboradas e analisadas 5 Cartas georreferenciadas, que apresentam as características físicas de uso do solo tanto no campus, quanto em seu entorno. 0 recorte temporal deste estudo destaca as transformações ocorridas a partir da instauração da universidade e da consolidação das ações do Programa do Federal de Apoio a Planos de Reestruturação e Expansão das Universidades Federais (REUNI) na UFJF. Resultados indicaram que nas duas áreas de análise houve um intenso processo de antropização e modificação no uso e ocupação do solo ao longo dos anos, com acréscimo considerável nas áreas construídas em detrimento da perda de cobertura vegetal, especialmente de áreas de vegetação rasteira; enquanto as áreas de solo exposto e de mata permaneceram relativamente estáveis. A implantação do REUNI, resultou em um impacto significativo no perfil da área construída do campus enquanto, no entorno, a urbanização foi mais constante desde a criação do campus nos anos 1960.

Palavras-chave: Uso do solo. Paisagem urbana. Campus universitário. REUNI.

ACCT é arquiteta e urbanista, graduada em Arquitetura e Urbanismo, e-mail: ana.tourinho@arquitetura.ufff.br SAB é arquiteta e urbanista, PhD em Ambiente Construído, e-mail: sabrina.barbosa@uerj.br CHBR é engenheiro civil, doutor em Geografia, e-mail: barra.rocha@engenharia.ufjf.br TOP é graduanda em Engenharia Ambiental e Sanitária, e-mail: tamires.prado@engenharia.ufjf.br KCA é arquiteto e urbanista, e-mail: klaus.alberto@ufjf.edu.br 


\section{Abstract}

This study aims to analyse how the campus of the Federal University of Juiz de Fora (UFJF) is configured as a structuring agent in the dynamics of the city from the study of the transformations in land use in the limits of the campus and in its immediate surroundings. For this, 5 georeferenced maps were developed and analysed, presenting the physical characteristics of land use both on the campus and in its surroundings. The time frame of this study highlights the changes that occurred since the establishment of the university and the consolidation of the actions of the Federal Program to Support Plans for Restructuring and Expansion of Federal Universities (REUNI) at UFJF. Results indicated that in both areas of analysis there was an intense process of anthropization and modification in the use and occupation of the land over the years, with a considerable increase in the built area at the expense of the loss of vegetation coverage, especially in areas of undergrowth, while the exposed land and forest areas remained relatively stable. The implementation of REUNI, resulted in a significant impact on the profile of the built environment of the campus while, in the surroundings, urbanization was more constant since the creation of the campus in the 1960s.

Keywords: Land use. Urban landscape. University campus. REUNI.

\section{Introdução}

0 estudo do Campus Universitário é relevante na medida em que esse equipamento, frequentemente, configura-se como núcleos complexos com amplas dimensões que representam particularidades do pensamento urbanístico de uma época. De acordo com Alshuwaikhat \& Abubakar (2008), as universidades podem ser consideradas "pequenas cidades" devido ao seu extenso tamanho, elevado contingente populacional e diversidade das atividades que ocorrem em seus campi. Nestes locais, os conflitos dos ideais urbanísticos se deparam com demandas específicas, sociais e culturais do espaço urbano. A implantação de um campus universitário desencadeia processos urbanos importantes, por isso podem ser associados a "mudanças na dinâmica e na estrutura intraurbana" destas cidades (Máximo 2020). Assim, as universidades e suas instalações se relacionam diretamente com o contexto urbano em que estão inseridas e sua localização pode se tornar um vetor de direcionamento da expansão urbana (Rodrigues, 2016).

O campus, como modelo de implantação de instituições de educação superior, nasceu no final do século XVIII com a fundação das primeiras universidades americanas. Contudo, após a Segunda Guerra Mundial, difundiu-se em outros países, inclusive na América Latina (Andrade \& Pavesi, 2012). No Brasil, projetos para universidades já vinham sendo realizados desde o início do século XX, entretanto, a criação da Universidade do Brasil (atual UFRJ) na década 1930 foi um marco na história do planejamento universitário nacional, pois propagou a ideia de que a construção de uma universidade deve estar relacionada com a construção de uma cidade universitária - muitas vezes embasada no modelo americano de campus universitário (Alberto, 2003).

Contudo, foi no governo de Juscelino Kubitschek, nas décadas de 1950 e 1960, que houve um significativo aumento no número de universidades federais no país. Foi justamente nessa época que o modelo americano de campus foi consolidado, quando as tendências da modernização brasileira se aproximaram de alguns paradigmas praticados nos Estados Unidos, tanto em termos de educação quanto de organização dos espaços para a sua prática (Alberto, 2008). Esses espaços são caracterizados pelo modelo de universidade-parque no qual os edifícios são implantados de forma setorizada de acordo com afinidades temáticas, seguindo princípios da arquitetura do movimento moderno. Este momento foi também marcado pela Reforma Universitária, implantada em 1968, que previa uma grande reestruturação, tanto física quanto acadêmica, do ensino superior. A consolidação do modelo de campus estabeleceu novos padrões de relacionamento da universidade com a cidade, criando áreas zonificadas para o ensino superior, afastadas das regiões urbanas centrais.

Depois da expansão universitária ocorrida no governo de Juscelino Kubitschek, em que foram criadas 16 novas universidades aumentando em $52 \%$ o número de universidades federais brasileiras, um segundo momento de crescimento ocorreu durante a década de 2000. Neste período, foram criadas e/ou 
federalizadas 19 novas universidades com a implantação de mais de 60 novos campi em todo o país (Medina, 2019). Essas iniciativas foram apoiadas por programas de incentivo como o REUNI - Programa de Reestruturação e Expansão das Universidades Federais - , criado no ano de 2007, com o objetivo de reestruturar e melhorar a qualidade do ensino superior brasileiro. 0 programa é considerado um marco na expansão do acesso ao ensino superior público brasileiro e estimulou a ida das universidades públicas para o interior do país, o que proporcionou além da criação de novos campi, a expansão dos existentes para atender as novas demandas (Máximo, 2020).

A Universidade Federal de Juiz de Fora (UFJF) é um dos empreendimentos que faz parte da expansão universitária ocorrida nas décadas de 1950/60. A Instituição foi a segunda universidade criada no interior do Brasil, diferente de outras que foram implantadas em grandes capitais, representando uma significante iniciativa para a cidade de Juiz de Fora e região. 0 Campus da UFJF também sofreu significativas alterações em um segundo momento de expansão, durante a década de 2000. Com a implantação do Programa do Governo Federal REUNI, a Instituição garantiu recursos para obras e melhorias necessárias para a própria evolução da universidade. Segundo Rocha et al. (2016), o campus da UFJF, com uma população de 27.600 usuários e 134,68 ha, está inserido em uma área urbana com grande crescimento imobiliário, o que acarreta a perda de áreas verdes, aumentando a geração de resíduos e efluentes. A presença do campus contribuiu para a realização de intervenções urbanas significativas para a cidade. A instituição é fortemente reconhecida como agente estimulador do desenvolvimento da cidade nos mais diversos setores. Juiz de Fora é conhecida como uma cidade universitária, devido ao impacto da UFJF na cidade ao longo dos anos. Com uma significativa oferta de cursos e vagas, a Instituição é responsável por transformar a economia e a dinâmica da cidade, trazendo alunos de diversas regiões do Brasil e do exterior. Além disso, a UFJF oferece diversos serviços para a comunidade da região, constituindo um polo de serviços educacionais e de saúde, além de estimular o desenvolvimento sociocultural da Zona da Mata mineira.

Estudos têm apontado que o desenvolvimento de um campus pode impactar a dinâmica da cidade provocando alterações no uso e ocupação do solo, atraindo investimentos do mercado imobiliário local tanto pela construção de novas edificações para locação quanto pela implantação de novos loteamentos e condomínios residenciais. Isso aumenta a demanda de produtos e serviços locais e, no campo da mobilidade, aumenta o tráfego motorizado e a demanda de transporte público (Sanfeliu, 2011; Pinheiro, 2018). Baumgartner (2015) destaca que a instauração e a expansão das universidades têm alterado significativamente "a estrutura urbana (conteúdo) e a própria morfologia das cidades (forma) que recebem esses novos campi" (Baumgartner, 2015, p. 86), o que pode resultar em impactos econômico, político e cultural. 0 estudo analisou os impactos ocorridos em cidades médias e pequenas a partir da expansão universitária na Bahia.

Duas publicações recentes também investigaram a produção do espaço urbano a partir da instalação e funcionamento de campi universitários. Máximo (2020) utilizou como estudo de caso dois municípios cearenses que receberam novos campi universitários a partir da implantação do REUNI. 0 estudo concluiu que a instalação das universidades acarretou alterações no espaço urbano para atender a nova demanda populacional. $\mathrm{O}$ autor destacou que o setor de serviços, mercado imobiliário, mobilidade urbana e até mesmo a legislação urbanística foi alterada, ainda que a implantação tenha se dado sem nenhum planejamento prévio para avaliar os impactos na cidade. A partir de uma análise que teve como foco a atuação de promotores imobiliários, Paula \& Faria (2020) descreveram como a expansão da Universidade Federal de Viçosa - MG (UFV) se constituiu um agente norteador na atuação do mercado imobiliário local. O estudo concluiu que a expansão da UFV gerou nova demanda por imóveis e serviços comerciais na zona central, em que se prevalece os interesses do capital imobiliário.

Neste sentindo, embora estudos tenham considerado os impactos da expansão de campi universitários na cidade, ainda são poucas as evidências do impacto dessas implantações no uso do solo do campus e no seu entorno ao longo do tempo. Os efeitos da recente expansão impulsionada pelo REUNI ainda precisam ser identificados e analisados para embasar potenciais futuros programas de investimento. Assim, este trabalho tem como objetivo analisar como o campus da Universidade Federal de Juiz de Fora (UFJF) se 
configura como um agente de transformação no uso do solo e estruturação na dinâmica da cidade a partir do estudo de suas transformações internas e de seu impacto no entorno imediato. Para avaliar como esse processo se deu no campus sede da UFJF, foi utilizado um recorte temporal com início em sua implantação nos anos 1960 até os dias atuais, por meio de análises de 5 Cartas georreferenciadas que destacam as transformações ocorridas a partir da instauração da universidade e da consolidação das ações do REUNI.

\section{A cidade de Juiz de Fora e a Universidade Federal de Juiz de Fora}

A cidade de Juiz de Fora localiza-se na mesorregião da Zona da Mata, localizada no sudeste do Estado de Minas Gerais (MG). Juiz de Fora é uma cidade de porte médio, com uma população de 516.247 habitantes (IBGE, 2010) e densidade demográfica de $359.59 \mathrm{hab} / \mathrm{km}^{2}$. A Carta Índice da Figura 1 apresenta a localização do Campus da UFJF na cidade e sua relação com as escalas do Brasil, do estado, da mesorregião e da microrregião.
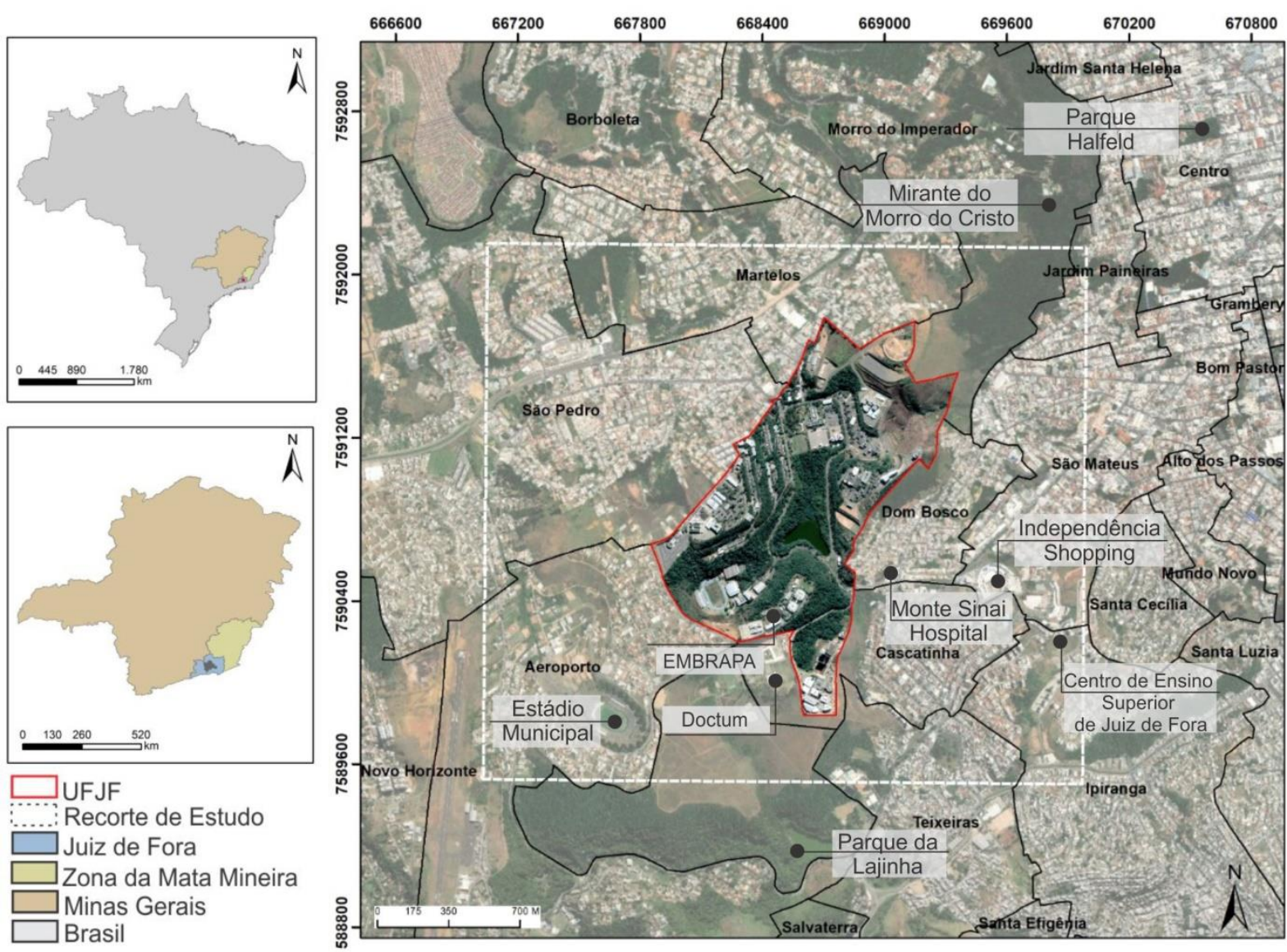

Figura 1 - Mapa de localização da Universidade Federal de Juiz de Fora e sua relação com as escalas do Brasil, do estado, da mesorregião e da microrregião. Fonte: Elaborado pelos autores (2020).

O campus da universidade, situado a 4,6 km do centro da cidade, está localizado no Bairro São Pedro, próximo aos bairros Aeroporto, Cascatinha, Dom Bosco, Morro do Imperador, Martelos e São Mateus. Sua implantação na região Oeste, conhecida como "Cidade Alta" pode ser considerada um dos marcos do processo "de descentralização da cidade, criando um novo eixo de expansão e valorização" (Geraldo, 2014, p. 114) que fomentou a modernização do sistema viário e da infraestrutura da região. Além de impulsionar o mercado imobiliário e o setor terciário, a universidade catalisou investimentos em seu entorno empregados em grandes equipamentos como a sede da Empresa Brasileira de Pesquisa Agropecuária (EMBRAPA), o Estádio Municipal, além de hospitais, shopping e universidades privadas. Além disso, o 
campus liga importantes seguimentos da cidade cujos deslocamentos podem ser efetuados por meio do seu anel viário interno (SETTRA, 2016).

A história da UFJF tem início no começo do século XX com o surgimento de vários cursos de ensino superior na cidade de Juiz de Fora, reconhecidos e federalizados na década de 1960. A UFJF contava, no início de sua história, com as faculdades de Ciências Econômicas, de Direito, de Farmácia e Odontologia e de Medicina, além da Escola de Engenharia, sendo posteriormente incluída a Faculdade de Filosofia e Letras. A Universidade foi criada por meio da Lei Federal $n^{\circ} 3.858$, em 23 de dezembro de 1960. 0 campus foi implantado em uma área total de 1.346.793,80 $\mathrm{m}^{2}$, doada pela prefeitura de Juiz de Fora.

Sua implantação foi iniciada no final da década de 1960 envolvendo grandes obras de terraplanagem realizadas em um terreno extremamente acidentado e finalizadas no início de 1970, em pleno regime ditatorial. 0 plano piloto do campus é constituído por oito plataformas que acompanham a acidentada topografia original (Souza, 2013). As plataformas reúnem edificações com atividades que concentram áreas de conhecimento específicas, utilizando a técnica de compensação do terreno por corte e aterro para a constituição dos platôs. Isso resultou em vários taludes ao redor de uma vasta área central destinada a atividades culturais, sociais e recreativas, que constitui uma área de integração no campus que, de acordo com o projeto piloto, deveriam ser implantados edifícios importantes como a Biblioteca Central, Reitoria, Restaurante Universitário, bem como cinema e museu. No entanto, algumas edificações do projeto original da UFJF, não foram executadas no momento inicial de implantação; apenas a Biblioteca Central e a praça cívica foram instaladas. 0 restante da área da plataforma central foi ocupado por vegetação. Somente recentemente, entre os anos 2009 e 2013 foram implantados um Centro de Convivência, uma pista de skate, equipamentos de ginástica e o Centro de Ciências com um Observatório e o Jardim Sensorial, caracterizando a plataforma central como um grande parque urbano. Outro aspecto relevante na concepção do Campus da UFJF, e que impactou diretamente a dinâmica da cidade, foi o sistema viário estabelecido.

Sua criação foi inspirada pelos princípios da Reforma Universitária que tinha como princípios básicos a flexibilidade, a expansibilidade, a compressibilidade. 0 que caracterizou a implantação de unidades-padrão, caracterizadas por projetos genéricos, baseados nas premissas da repetição de elementos construtivos e da adoção de sistemas construtivos racionais, sem definição específica quanto à função (Souza, 2013). Esse processo acompanhou o ritmo acelerado que ditou a concepção de muitos campi brasileiros nas décadas de 1960 e 1970 resultou em fragilidades de projetos, uma vez que foram desenvolvidos a partir de diretrizes de caráter geral que nortearam o plano piloto e os projetos executivos das edificações. Essas instalações caracterizaram-se pela reprodução de projetos e repetição de elementos construtivos como forma de promover economias e facilitar as obras. Embora o curto prazo para a realização dos projetos favorecesse a racionalização da construção e a centralização das decisões de projeto, isso resultou em danos na qualidade dos espaços, não considerando as necessidades de seus futuros ocupantes e nos conteúdos projetuais locais e individualizados (Andrade \& Pavesi, 2012). Assim, os projetos careceram de programas de necessidades específicos, apurados e alinhados com as peculiaridades de cada curso, como laboratórios específicos, gabinetes de trabalho, bibliotecas setoriais, cantinas e outros (Souza, 2013).

No campus da UFJF, contudo, foram considerados aspectos flexíveis e racionais que permitiram que os espaços da universidade recém-implantada, paulatinamente e ao longo do tempo fossem moldados às necessidades dos futuros usuários (Souza, 2013). Assim, percebe-se a relação entre as decisões tomadas na implantação do Campus com as diretrizes racionalistas da Reforma Universitária de 1968 e as motivações desenvolvimentistas do período.

O Programa MEC/BID III assegurou à Universidade uma segunda fase de crescimento que, devido à sua importância, pode ser considerada como um primeiro momento de consolidação do seu campus. Nessa fase, foram introduzidos novos elementos de projeto, porém com detalhamentos para atender às funções específicas relacionadas ao desempenho das tarefas pedagógicas. Segundo Souza $(2013$, p. 109), os detalhamentos "foram mais acentuados do que a ênfase na racionalidade e nos aspectos de economia de escala da implantação inicial", caracterizados pela introdução de edifícios singulares, diferentemente das unidades-padrão da primeira fase de implantação do campus. Mesmo com esses investimentos na 
estruturação física do campus, até os anos 2000 a UFJF ainda mantinha algumas unidades acadêmicas, de serviços e mesmo a Reitoria, distribuídos na área central da cidade. Nesse início de década foi feito um esforço para concentrar no campus suas principais áreas de atividades. Para isso, foi construído um setor de saúde e um novo hospital universitário, que se localizou fora do limite do anel viário, aumentando assim o limite construído do campus. Nesse período, o edifício da biblioteca central foi adaptado para receber a reitoria e as unidades acadêmicas administrativas, antes dispersas fora do campus.

Uma nova fase de expansão e consolidação ocorreu ainda nessa década com a implantação do REUNI em território nacional. No ano de 2007, a instituição garantiu junto ao Governo Federal, recursos para obras e melhorias necessárias à própria manutenção e crescimento da universidade. Após a implantação do REUNI, verificou-se que o número de cursos e consequentemente a população acadêmica aumentaram gradativamente. Com isso, a estrutura física foi ampliada, o que resultou em um grande volume de obras no Campus, a fim de atender o aumento significativo do número de matrículas oferecidas pela Instituição. Isso resultou na contratação de mais de 114 obras no período de 2007 a 2017, segundo Júnior (2019). A Figura 2 indica os setores e os principais edifícios no espaço do campus atualmente.

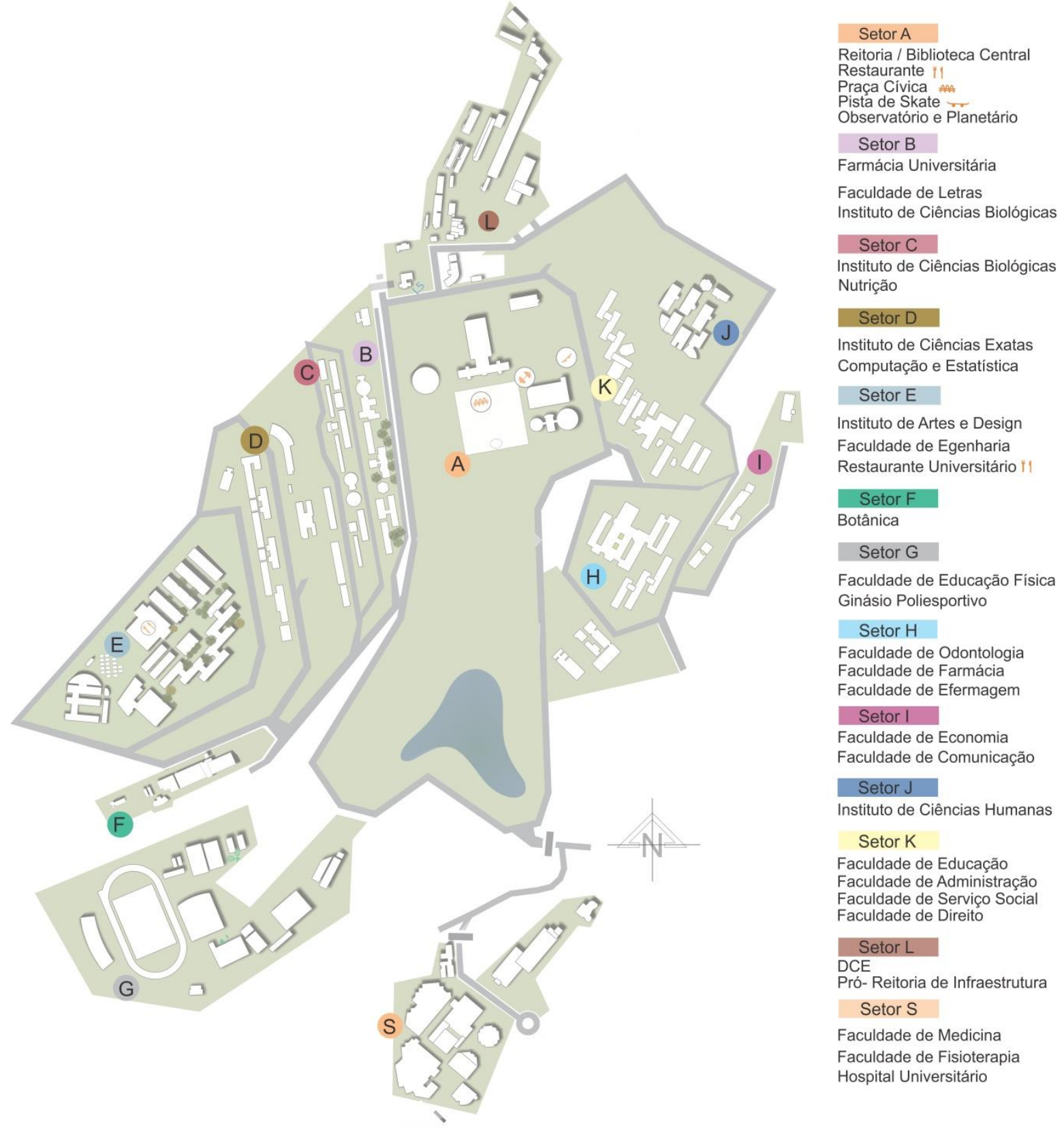

Figura 2 - Mapa geral do campus com indicação dos principais setores e edifícios. Fonte: Elaborado pelos autores (2020). 


\section{Material e Método}

Este trabalho foi realizado por meio do desenvolvimento de 5 Cartas georreferenciadas de Uso e Ocupação do solo a partir de imagens do Campus da UFJF em diferentes anos. As imagens foram escolhidas considerando um intervalo temporal de acordo com os objetivos do estudo e a disponibilidade cartográfica para o período de análise. Além disso, o recorte espacial da análise considerou o limite do campus na sua atual configuração, adicionado a aproximadamente $1,2 \mathrm{~km}$ de entorno em todas as laterais. Ressalta-se ainda que o entorno selecionado foi determinado a partir da possibilidade de visualização satisfatória da imagem em todos os anos analisados.

A primeira Carta foi desenvolvida a partir da imagem que mostra o momento inicial de implantação do campus, em 1968; a segunda imagem, de 1983, permite verificar o campus em um estágio de consolidação que durou desde a década de 1980 até os anos 2000; a terceira Carta trata do momento inicial do REUNI, em 2007; por fim, as Cartas de 2012 e 2019 permitiram avaliar de forma mais detida os impactos do REUNI. As Cartas dos anos de 1968, 1983 e 2007 tiveram como fonte primária as ortofotos digitalizadas para as duas primeiras e digital para a terceira da base cartográfica da Prefeitura Municipal de Juiz de Fora com resolução de 5m, $2 \mathrm{~m}$ e 0,5m, respectivamente. As imagens de 2012 e 2019 foram obtidas a partir do servidor Google Earth Pro, com resolução de 5m, cuja escala escolhida foi a de 1:10.000. As Cartas foram elaboradas e analisadas através do software ArcGIS 10.2.1 e retratam as modificações na paisagem urbana ao longo dos anos.

Os procedimentos metodológicos desta pesquisa fundamentam-se na avaliação das transformações morfológicas no espaço do Campus da UFJF e seu entorno na cidade de Juiz de Fora, desde sua implantação até os dias atuais. As Cartas desenvolvidas apresentam as mudanças no uso do solo e identificam 4 formas de ocupação: edificações/área urbanizada, vegetação arbórea, vegetação rasteira e solo exposto. Essas áreas foram definidas a partir da criação de polígonos feitos manualmente com o auxílio da ferramenta polígono do ArcToolbox do Arcgis 10.2.1. Por fim, foi utilizada a ferramenta field calculator para o cálculo das áreas em $\mathrm{km}^{2}$.

\section{Resultados e Discussão}

\section{Implantação e consolidação do campus}

A primeira Carta analisada, do ano de 1968, apresentada na Figura 3, mostra o início do desenvolvimento do campus, que foi implantado em uma região pouco adensada. A imagem ilustra como a topografia do campus foi movimentada e ajustada em função das soluções projetuais adotadas. Dentro dos limites do campus é possível identificar também a presença de focos pontuais e pouco representativos de vegetação adensada (mata), além de solo exposto nas áreas que foram implantados os platôs prévios às futuras construções, correspondendo a 18,5\% e 9,6\% da área total do campus, respectivamente. Percebe-se ainda a predominância de pastagens com vegetação rasteira, o que correspondia, nesse momento, a 70,4\% da área total do campus.

Nesse período, o entorno do campus se configurava como área de baixa ocupação urbana (31\%), com predominância de áreas de vegetação rasteira (56,3\%). Contudo, é possível verificar o início da construção de vias e trajetos para a incorporação de novos loteamentos. No final da década de 1970 foi desenvolvido um Plano Diretor para a região com a clara intenção de incentivar sua expansão, que já contava com a implantação do campus e com loteamentos e condomínios residenciais (Prefeitura de Juiz de Fora, 2000). 

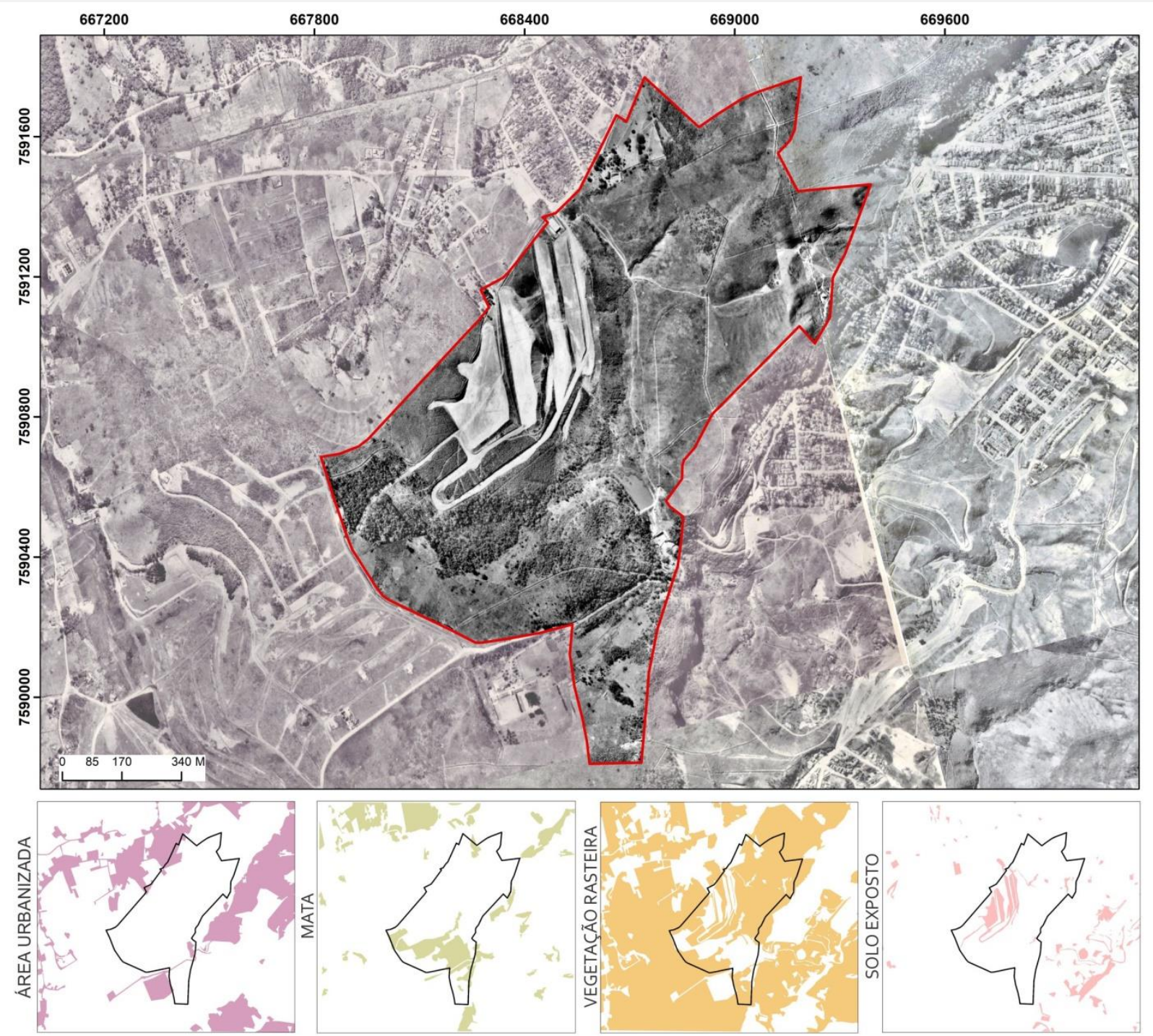

Figura 3 - Limite do Campus da Universidade Federal de Juiz de Fora destacado na imagem área de 1968. Fonte: Prefeitura de Juiz de Fora (2019), adaptado pelos autores.

A Figura 4 apresenta uma Carta produzida a partir de uma imagem de 1983, que mostra um avanço na consolidação do campus. Nesse momento, a UFJF se beneficiava dos avanços tecnológicos da década de 1980 no Brasil e do Programa MEC/BID III. Na imagem, é possível observar algumas obras deste período de expansão, como o Centro de Línguas, o Centro de Processamento de Dados (CPD), a Faculdade de Odontologia e o Centro Pedagógico, atuais Faculdades de Comunicação e Educação. Além disso, nesta imagem se observa a formação do Lago dos Manacás na plataforma central. A área construída dentro do limite do campus passou a representar $23 \%$ da área avaliada, enquanto a vegetação rasteira ocupava $47,4 \%$.

Na paisagem urbana do entorno percebe-se uma inversão das áreas não ocupadas, uma vez que a área coberta por vegetação rasteira ocupava, neste momento, 37,8\% da área analisada, diminuindo em 18,5\% em relação à Carta anterior. Por outro lado, as áreas urbanizadas e de mata aumentaram, ocupando 35\% e 18,5\% da área de análise, respectivamente. Neste período, foram criados uma alça viária e um viaduto de acesso ao campus, o que facilitaram a conexão do campus com a região central da cidade. 

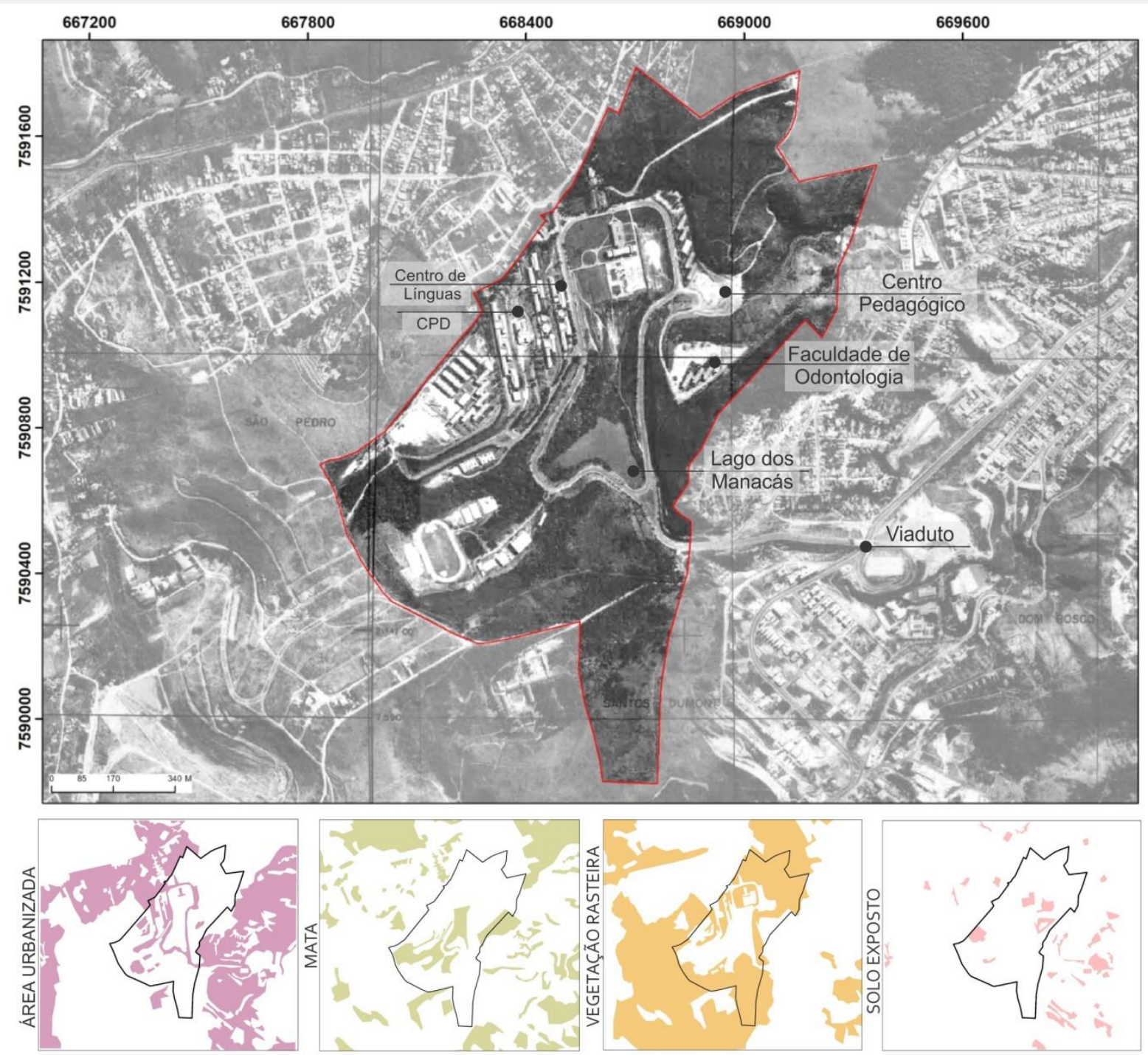

Figura 4 - Limite do Campus da Universidade Federal de Juiz de Fora destacado na imagem área de 1983. Fonte: Prefeitura de Juiz de Fora (2019), adaptado pelos autores.

Após a década de 1980, até o início da década de 2000, a Instituição viveu um longo período de estagnação, sem grandes obras de infraestrutura e expansão de sua estrutura física. A Figura 4, relativa ao período de 2007, apresenta estrutura próxima à consolidada na década de 1980, com a finalização das obras do programa MEC/BID III. Como consequência, neste período tem-se que a área construída do campus correspondia a 34,1\% de sua área total, configurando em um aumento de 11\% em relação à Carta de 1983. Parte considerável desse aumento se deu a partir da instalação do Setor de Saúde, que foi concluído com a implantação do REUNI. É importante destacar, também, as edificações da Empresa Brasileira de Pesquisa Agropecuária (EMBRAPA) Gado de Leite e a terraplenagem do Centro de Políticas Públicas e Avaliação da Educação (CAED), próximos à área do Setor de Saúde, localizados fora do limite do anel viário, aumentando assim o limite construído do campus. Ainda sobre a paisagem interna ao Campus nesse período (Figura 5) fica evidente o desenvolvimento natural da área de mata que configura-se de forma fragmentada entre as edificações na Universidade, correspondendo a 31,9\% da área do campus, além da forte presença de áreas de vegetação rasteira $(26,7 \%$ da área do campus).

No entorno, é importante destacar um expressivo adensamento da área construída, passando a ocupar 65\% do solo em 2007; isso ocorreu juntamente com a implantação de grandes equipamentos, dentre eles o Estádio Municipal, Hospital Monte Sinai e Independência Shopping. Esse adensamento foi acompanhado pelo crescimento populacional da cidade, que foi de cerca de 48\% em 2000, em relação a 1980 (IBGE, 2000). 0 Plano Diretor de Juiz de Fora considerou a região como de grande interesse de ocupação, o que exigiu ações para evitar um adensamento 
desproporcional à infraestrutura urbana existente. Nesse Plano ainda é reconhecida a importância do anel viário do campus para as conexões entre regiões da cidade (Prefeitura de Juiz de Fora, 2000).
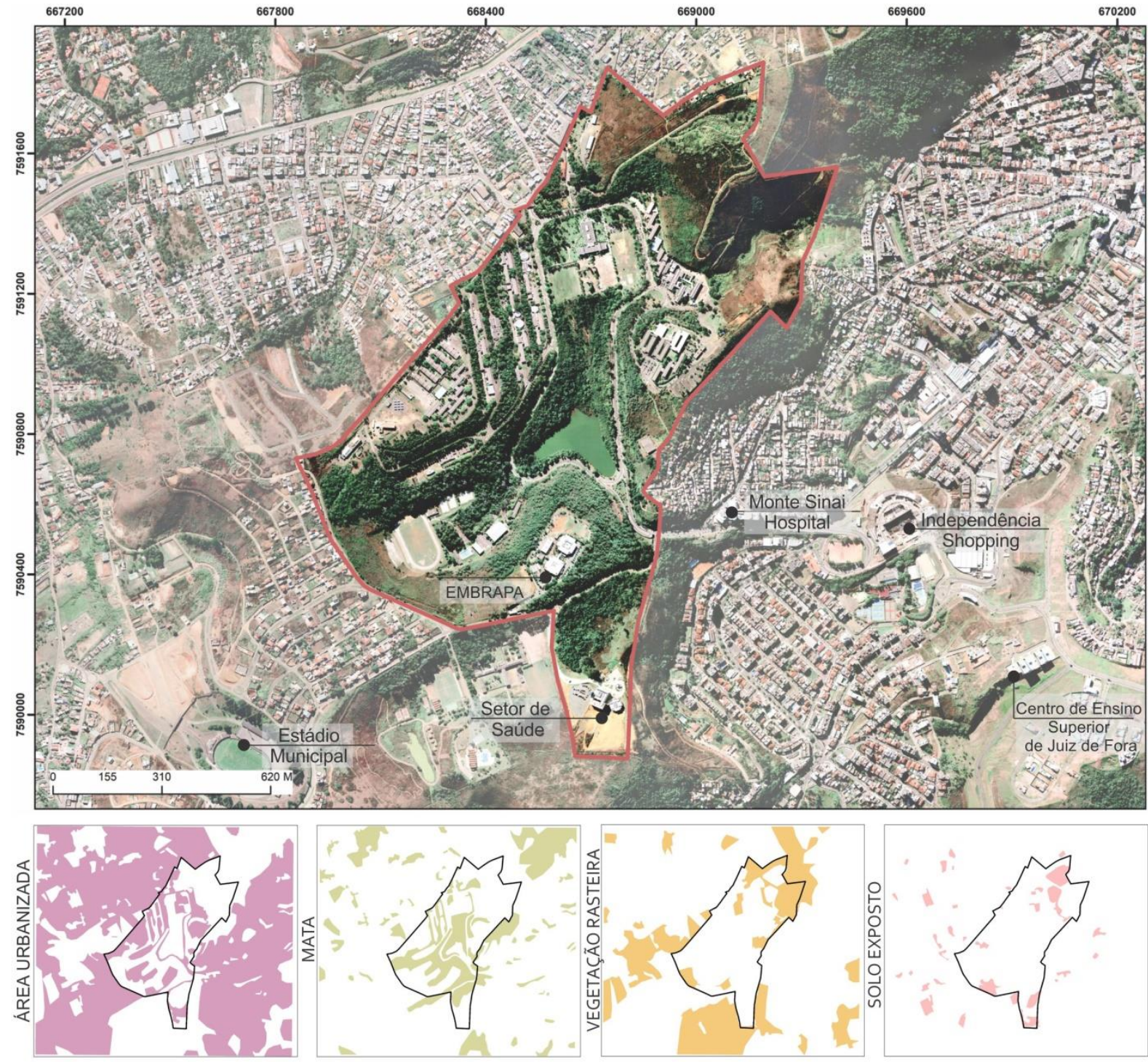

Figura 5- Limite do Campus da Universidade Federal de Juiz de Fora destacado na imagem área de 2007. Fonte: Prefeitura de Juiz de Fora (2019), adaptado pelos autores.

\section{Transformações a partir da implantação do REUNI}

A adesão da UFJF ao REUNI deu-se em 27 de outubro de 2007. Os reflexos na paisagem interna do campus foram percebidos a partir da expansão das instalações da Universidade, marcadas por várias obras, a fim de atender o aumento expressivo no número de matrículas na Universidade. De acordo com Júnior (2019), o número de matrículas na instituição, considerando graduação e pós-graduação, praticamente dobrou em um intervalo de 10 anos, passando de 11.246 em 2007 para 21.055 em 2017, além da ampliação no número de servidores e docentes. Segundo Geraldo (2014), em 2007, 42\% dos alunos da instituição vinham de outras cidades, o que impulsionou o mercado imobiliário no entorno e aumentou os fluxos diários. Ainda vale destacar que o crescimento populacional dos bairros adjacentes ao campus foi expressivo em relação ao crescimento do restante da cidade. A população da região urbana São Pedro aumentou cerca de $40 \%$ no período de 2000 a 2010, enquanto o crescimento de outras regiões da cidade se mostrou estável, de acordo com dados do IBGE, 2010.

Para subsidiar a expansão projetada para a UFJF, foram realizados investimentos na ampliação da estrutura física existente por meio da construção de novas unidades acadêmicas e administrativas, além de 
reformas de edificações. A imagem da Figura 6, relativa ao ano de 2012, mostra os impactos do programa REUNI na reestruturação do espaço da universidade, apresentando algumas obras já concluídas e outros terrenos preparados para receber a construção de novas edificações e expansões futuras. Essas últimas estão localizadas em platôs próximos aos limites do campus, que se caracterizam nas imagens pelos solos expostos. Essa representação expõe os novos contornos dentro dos limites do campus e uma estruturação mais clara de novos centros. Neste momento, a área urbanizada correspondia $46 \%$ da área do campus, enquanto o solo exposto representava 9,6\%. Fica evidente também a diminuição das áreas verdes, que ocupavam nesse momento $28 \%$ do terreno. Com isso, houve um espraiamento das áreas impermeáveis e de construções. As áreas que antes possuíam vegetação densa e rasteiras foram alteradas e adaptadas para atender às necessidades do projeto de expansão.

0 entorno do campus se apresentava com um crescimento acelerado, principalmente à noroeste, com um núcleo de edificações mais adensado em relação aos anos anteriores. Nesta Carta, fica clara a consolidação de condomínios e loteamentos na região, apontada pelo IBGE (2010) como principal vetor de crescimento do município. De acordo com Tasca \& Amaral (2012), a grande maioria dos condomínios da cidade de Juiz de Fora se concentrava na região da Cidade Alta. Como consequência, observa-se que a área urbanizada ocupava, neste momento, $71,5 \%$ da área analisada, enquanto discretos núcleos de vegetação mais espessas representam 10,3\%.
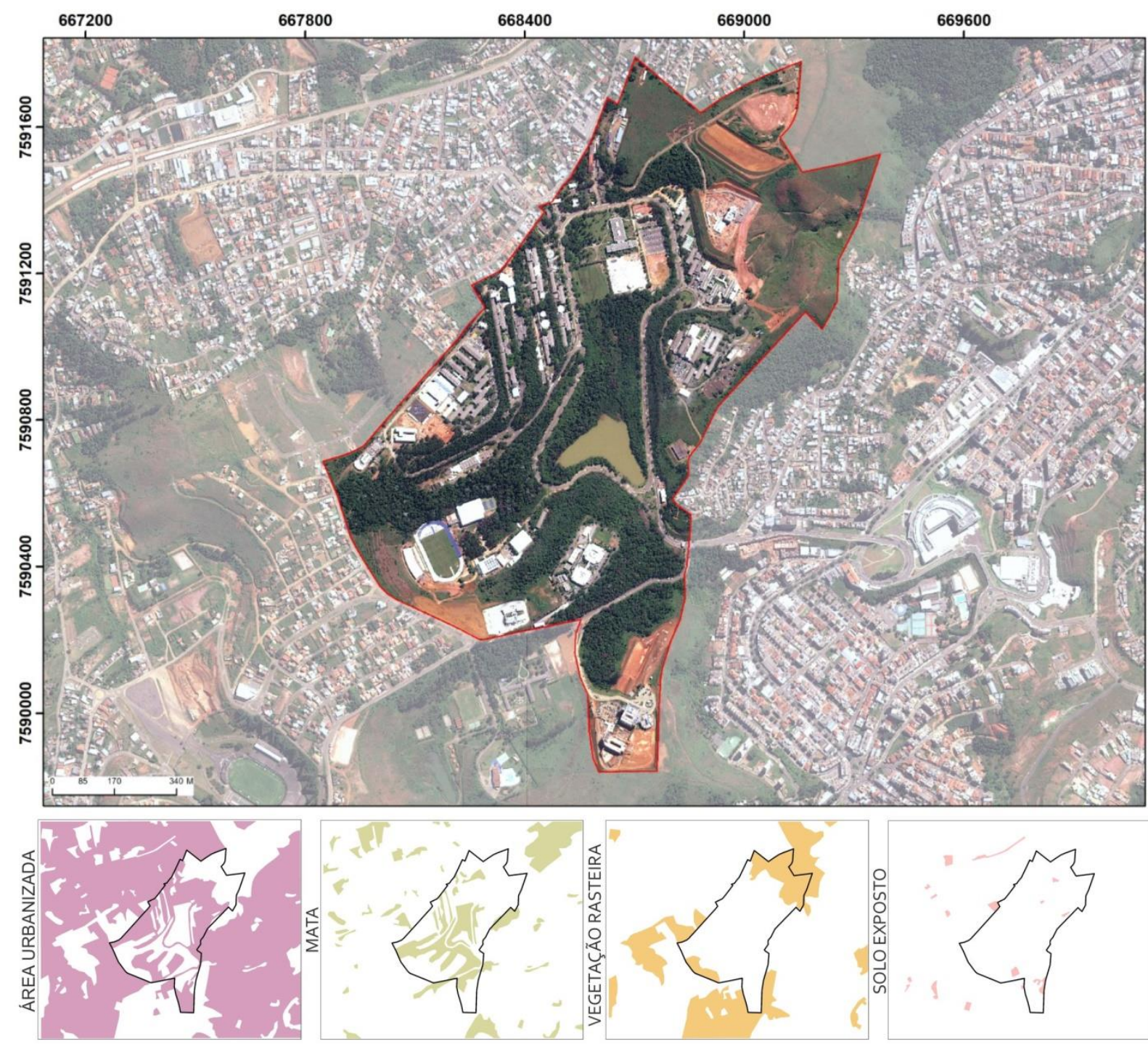

Figura 6 - Limite do Campus da Universidade Federal de Juiz de Fora destacado na imagem área de 2012. Fonte: Google Earth Pro (2019), adaptado pelos autores.

Com uma representação referente ao ano de 2019, a Carta da Figura 7 apresenta a morfologia do campus semelhante à Carta anterior. A paisagem interna é marcada por poucas alterações. Os platôs, que 
antes se caracterizavam por áreas expostas, encontram-se nesse período recobertos por construções, que correspondem a 48,9\% da área do campus, representando um aumento de $15 \%$ em relação à área construída em 2007. A área de núcleos de vegetação mais adensada (mata) no interior da Universidade, embora tenham aumentado, se mantém bem próxima à realidade de 2007. Além disso, essa Carta indica que apenas $18,5 \%$ do solo é caracterizado por vegetação rasteira ou solo exposto, enquanto esse valor era de $34,1 \%$ em 2007. Vale destacar que a retirada da cobertura vegetal associada à impermeabilização do solo pelo aumento do espaço construído pode contribuir para o aumento do escoamento superficial da água no solo e para o assoreamento do Lago dos Manacás, localizado na plataforma central do Campus. Segundo Rocha et al. (2016), o Lago apresenta a sua água com qualidade cada vez pior, admitindo usos preponderantes apenas para navegação e harmonia paisagística.

Percebe-se que o entorno da universidade se manteve no ritmo marcado pelos anos anteriores, com a ampliação dos aglomerados de edifícios e condomínios, que nesse momento correspondem a $72 \%$ do entorno de análise, valor muito próximo ao ano de 2012. Esta última Carta mostra ainda que áreas de mata no entorno permaneceram próximas aos valores identificados em 2007.
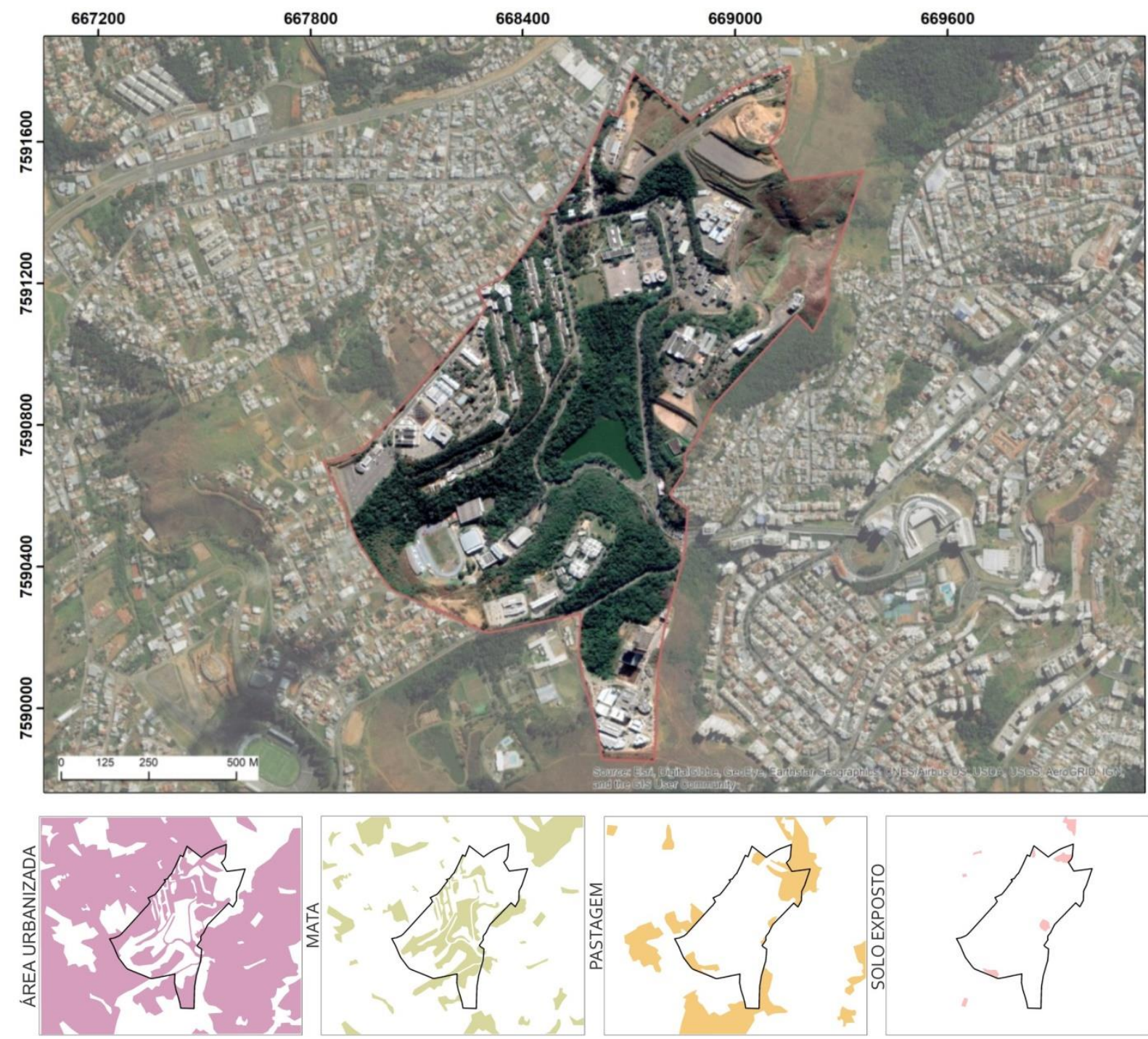

Figura 7 - Limite do Campus da Universidade Federal de Juiz de Fora destacado na imagem área de 2019. Fonte: Google Earth Pro (2019), adaptado pelos autores.

A Figura 8 apresenta, de forma quantitativa, as transformações no uso e ocupação do solo nos anos analisados nos limites do campus (a) e no seu entorno (b). Percebe-se que a tendência de transformações, tanto no campus quanto no seu entorno, ao longo dos anos foi similar em relação à diminuição acentuada 
da área de vegetação rasteira e uma diminuição discreta da área de solo exposto. A área urbanizada, por outro lado, teve um crescimento distinto no campus e no entorno.

Dentro do campus, percebeu-se um crescimento significativo da área urbanizada desde o período de sua criação até sua consolidação na década de 1980, com o projeto MECBID. Um crescimento menos acentuado foi, contudo, observado entre os 24 anos que separam as Cartas de 1983 e 2007. Uma nova guinada foi observada em apenas 5 anos de instalação do REUNI, além de um novo crescimento menos acentuado entre 2012 e 2019, quando a área urbanizada ocupa cerca de 49\% de seus limites. Quanto à área de mata, o campus manteve um crescimento relativamente estável, principalmente pela ocupação de áreas que antes eram de vegetação rasteira, atingindo aproximadamente 33\% em 2019, apresentando uma distribuição mais equilibrada com a área construída.

$\mathrm{Na}$ área de entorno do campus, embora o crescimento da área urbanizada foi de cerca de $41 \%$ aos dos anos de análise, esse se deu de forma mais acentuada entre os anos de 1983 e 2012. Após esse período, houve uma pequena variação até 2019. Contudo, o percentual de 70\% de área urbanizada no entorno do campus em 2019, em contraponto ao percentual de 49\% no campus, expressa a forte urbanização do entorno. Essa é reflexo da atuação do mercado imobiliário que, de maneira semelhante ao que foi registrado no estudo sobre o campus da UFV (Paula \& Faria, 2020), atua ressignificando o entorno dos campi criando novas centralidades. Em contraposição, a área de mata do entorno do campus manteve um percentual baixo e relativamente estável entre 1968 e 2019, próximo aos 13\%. Essa análise também pode ser visualizada pela Figura 9, que apresenta uma sequência de imagens cronológica do campus.

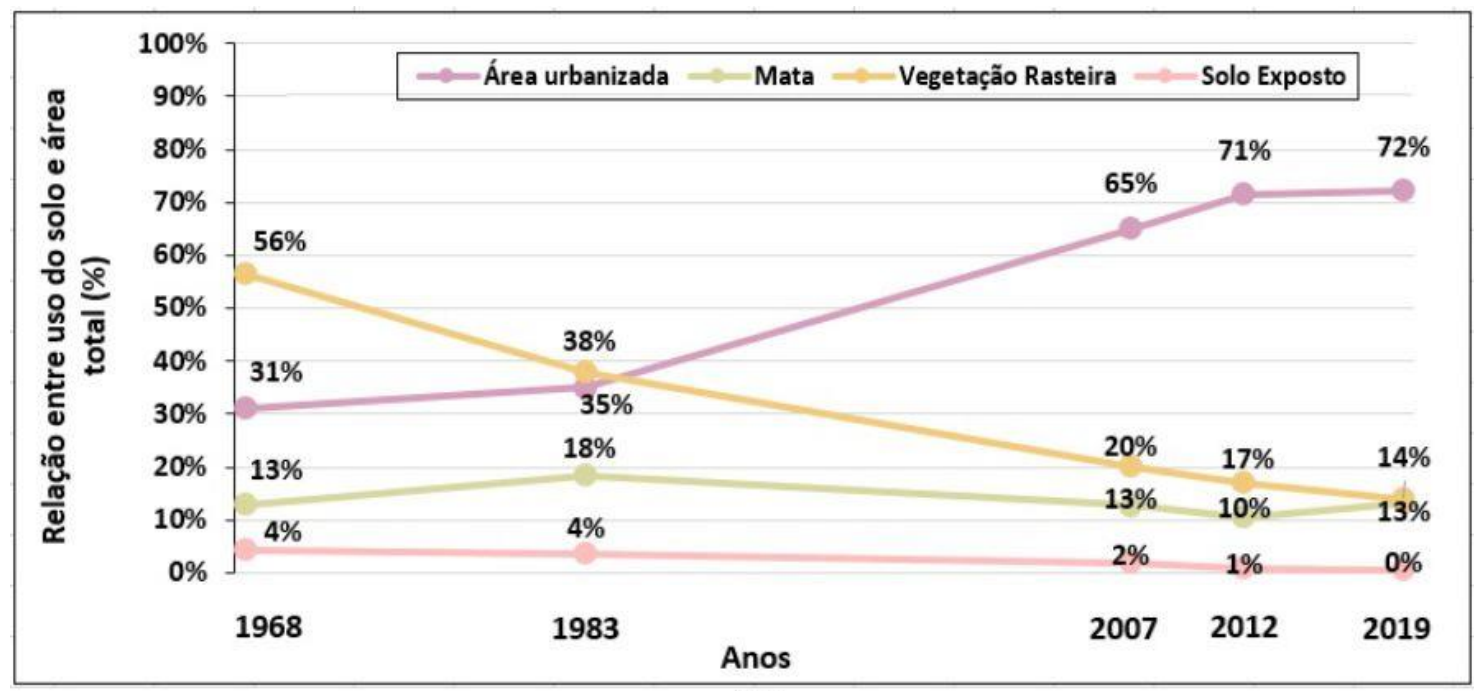

(a)

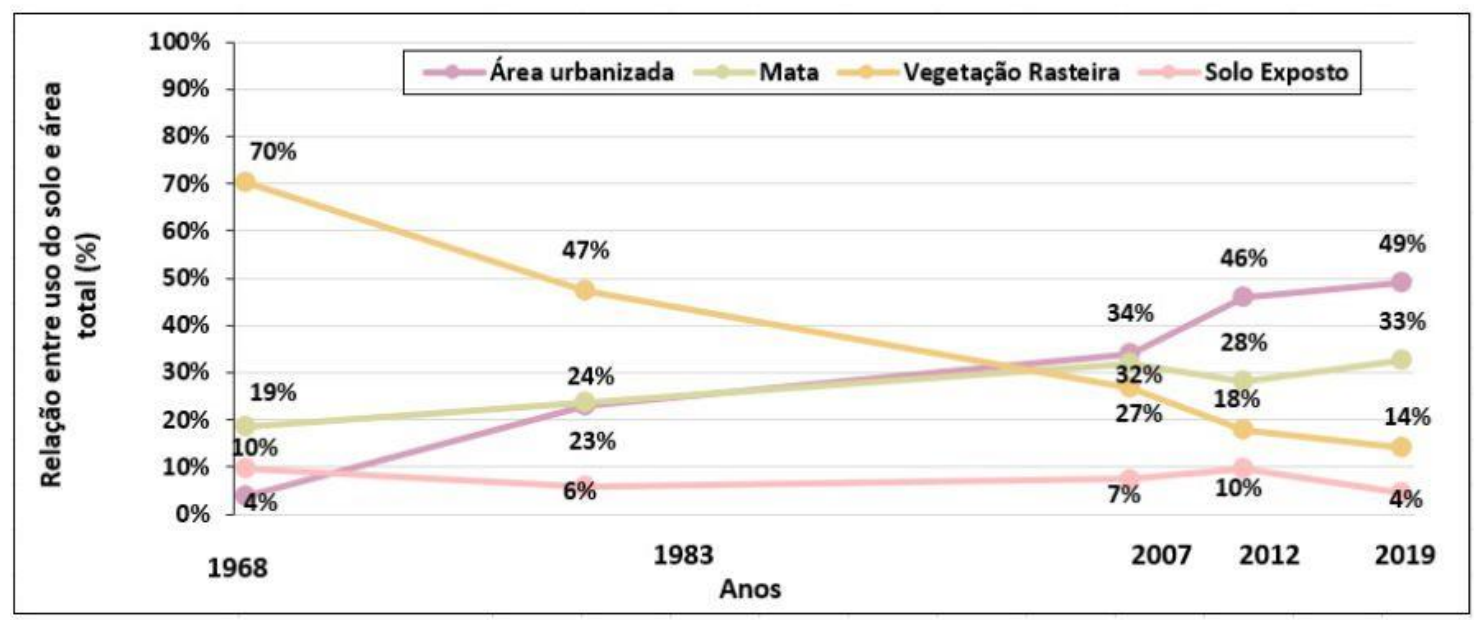

(b)

Figura 8 - Análise das áreas dos tipos de solo calculados nos limites do campus (a) e no entorno avaliado (b). Fonte: Elaborado pelos autores (2020). 


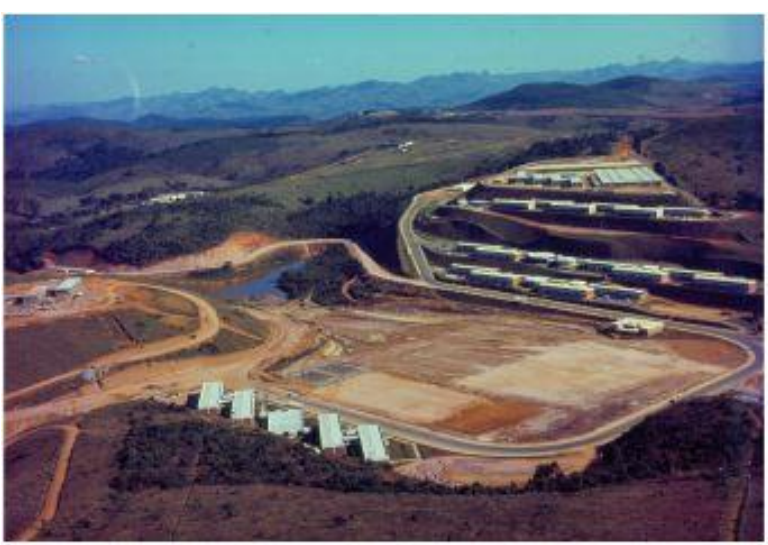

1970

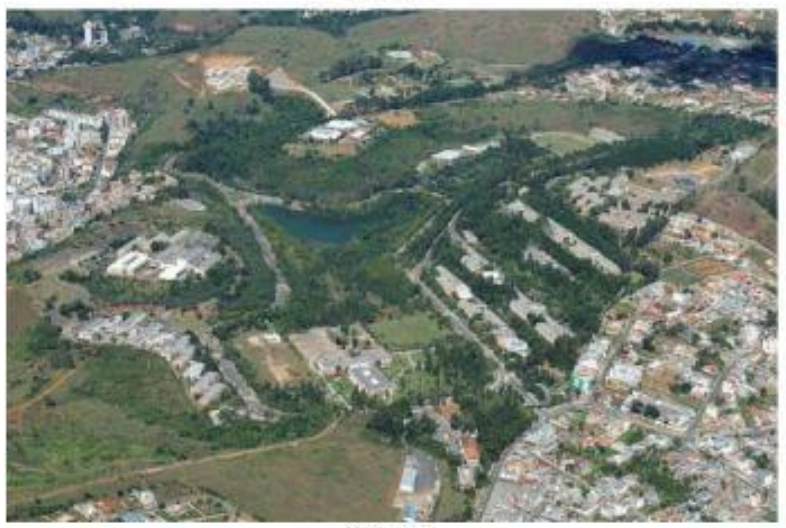

2006

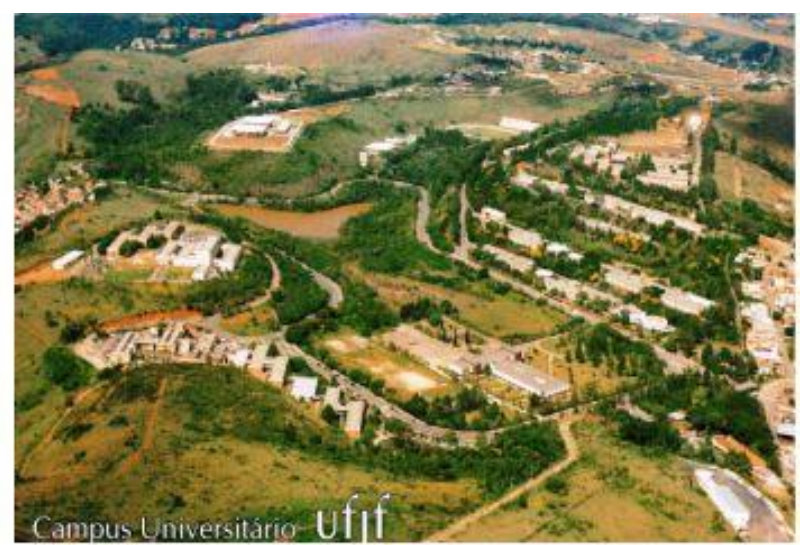

1988

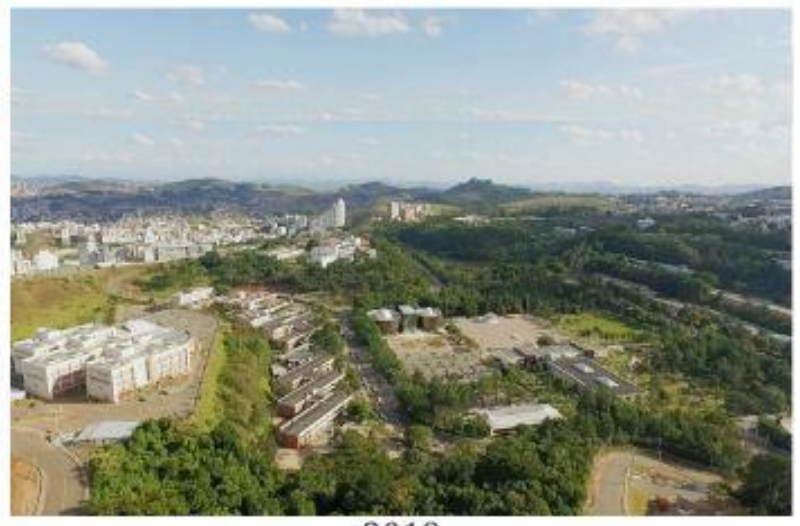

2019

Figura 9 - Imagens da Universidade ao longo do tempo. Fonte: Roberto Dornellas e Arquivo central da UFJF.

Pelas fotos, percebe-se que a conformação montanhosa do campus e seu consequente adensamento em platôs é um limitante do acesso e da caminhabilidade no espaço, cujos aspectos são importantes para a vida acadêmica. Além disso, o campus, por fazer parte do sistema viário da cidade, constitui-se em uma área estratégica de tráfego de passagem, o que também pode ter contribuído para o adensamento da chamada Cidade Alta. Esse processo de adensamento da área de análise também pode ser visualizado a partir da Figura 10, que apresenta o aumento do número de vias no campus e no entorno ao longo dos anos. As linhas em vermelho representam novas vias criadas nos anos correspondentes, de forma progressiva.

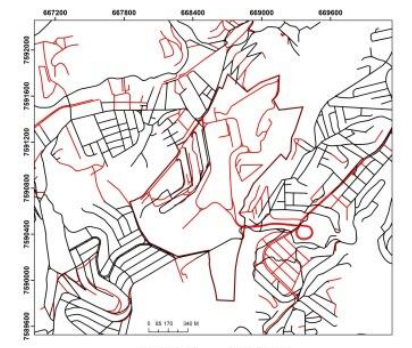

$1968-1983$

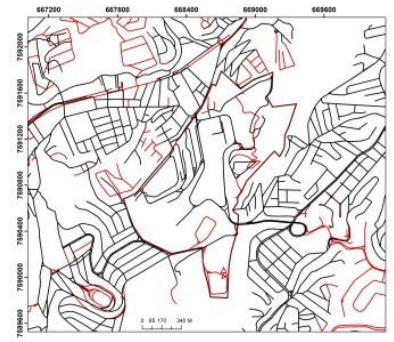

$1983-2007$

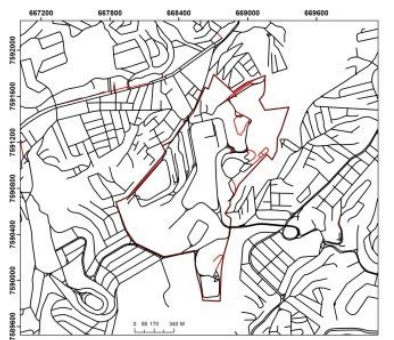

$2007-2012$

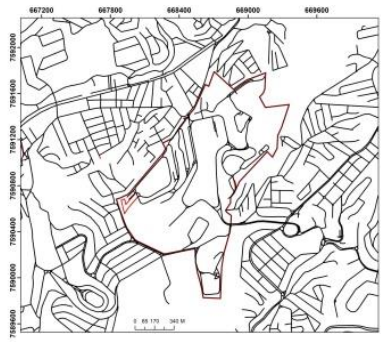

$2012-2019$

Figura 10 - Implantação de vias ao longo do tempo no campus e em seu entorno. Fonte: Elaborado pelos autores (2020).

$\mathrm{Na}$ área analisada percebe-se que a maior parte das vias foram criadas nas duas primeiras décadas a partir da instauração do campus da UFJF, entre 1968 e 1983, quando esse aumento foi de 39\%. Entre os anos de 1983 e 2007, o aumento nas vias de toda a área analisada representaram 18\%, enquanto nos 5 anos após o REUNI esse crescimento se deu principalmente dentro do campus. Já entre 2012 e 2019, esse aumento foi inexpressivo. Assim, a tendência de crescimento no número de vias é similar ao crescimento da 
área urbanizada. É importante destacar que o aumento das vias acarretou um volume significativo de tráfego de veículos do campus, principalmente nos acessos, o que causa congestionamentos, principalmente em horários de pico, além de acidentes e outros impactos na segurança. 0 Plano de Mobilidade de 2016, desenvolvido para a cidade de Juiz de Fora, citou a região do campus como uma região mal articulada em termos de mobilidade e estruturação viária e de circulação, indicando sinais de saturação e geradores de tráfego em seu entorno. A proposta confirma "a necessidade da busca de soluções que possam eliminar as precárias condições operacionais verificadas na região". Além disso, o Plano evidencia a falta de um planejamento para a região da Cidade Alta, que apresenta um índice de ocupação elevado, articulado ao aumento na circulação, o que pode ser correlacionado ao aumento no número de vagas, inclusive de veículos oriundos dos diversos municípios situados no seu entorno (SETTRA, 2016). Essa demanda pela revisão da legislação, e mesmo da infraestrutura do entono dos campi universitários para a melhoria da mobilidade urbana, é um ponto também registrado em outros estudos sobre o impacto de espaços universitários em cidades brasileiras (Máximo, 2020).

\section{Conclusões}

Este estudo teve como objetivo analisar as transformações no uso do solo (área urbanizada, mata, vegetação rasteira e solo exposto) do Campus da Universidade Federal de Juiz de Fora (UFJF) e do seu entorno imediato a partir desenvolvimento e análise de Cartas georreferenciadas de cinco anos estratégicos: 1968, 1983, 2007, 2012 e 2019. Assim, foi possível entender como o espaço foi alterado, com reorganizações e mudanças em sua paisagem, principalmente a partir da implementação do REUNI.

A partir da linha temporal traçada, foi possível entender a importância e o contexto da implantação do campus e os impactos em seu entorno. Nas áreas analisadas, houve um intenso processo de antropização e modificação no uso e ocupação do solo ao longo dos anos, com um acréscimo considerável nas áreas construídas em detrimento da perda de cobertura vegetal, especialmente de áreas de vegetação rasteira. É importante destacar a importância ambiental de tais áreas, uma vez que podem potencialmente evoluir para vegetação arbórea. Assim, a redução da cobertura vegetal rasteira pode implicar em perdas ambientais significativas e na qualidade de vida.

A implantação do REUNI, especialmente entre 2007 até 2012, teve um impacto significativo no perfil da área construída do campus enquanto, no entorno, a urbanização foi mais constante desde a criação sua criação nos anos 1960. Esse fato sugere que o impacto de um campus em seu entorno pode ser melhor visualizado em sua longa trajetória, pois a temporalidade da cidade formal contrasta com a temporalidade da cidade universitária. É importante notar, contudo, que o método usado nesse estudo não permitiu uma leitura da verticalização dos espaços, o que permitiria uma análise mais aprofundada das consequências desse tipo de processo de expansão ao longo dos anos.

Percebe-se que a expansão do campus da UFJF não seguiu parâmetros pré-estabelecidos em planos de ocupação, muitas vezes pela ausência dos mesmos. Assim, ressalta-se a importância do desenvolvimento de planos diretores como norteadores de novas unidades acadêmicas, especialmente com a atual disponibilidade de novas áreas de expansão criadas pelos platôs recentemente criados, mas ainda não ocupados. Percebe-se também a necessidade de que esses novos planejamentos considerem, especialmente, um plano de cobertura vegetal para manter a paisagem natural do campus, pois, com o baixo percentual das áreas verdes do entorno, seus benefícios ambientais tornam-se fundamentais para toda a região.

\section{Referências}

Alberto, K. C. (2003). Três Projetos para uma Universidade do Brasil (Dissertação de Mestrado). Programa de Pós-Graduação em Urbanismo, Universidade Federal do Rio de Janeiro, Rio de Janeiro.

Alberto, K. C. (2008). Formalizando o ensino superior na década de 1960: A cidade universitária da UnB e seu projeto urbanístico (Tese de Doutorado). Faculdade de Arquitetura e Urbanismo, Universidade Federal do Rio de Janeiro, Rio de Janeiro. 
Alshuwaikhat, H. M., \& Abubakar, I. (2008). An integrated approach to achieving campus sustainability: assessment of the current campus environmental management practices. Journal of Cleaner Production, 16, 1777-1785.

Andrade, C. R. M. de, \& Pavesi, A. (2012). O Planejamento de campi Universitários como Prática Participativa e Educativa. Revista Brasileira de Estudos Urbanos e Regionais, 14(1), 187-196. http://dx.doi.org/10.22296/23171529.2012v14n1p187.

Baumgartner, W. H. (2015). Cidades universitárias, cidades medias, cidades pequenas: análises sobre o processo de instalação de novos campi universitários. Espacio Abierto, 5(1), 73-

93. http://dx.doi.org/10.36403/espacoaberto.2015.2525

Brasil. (1960, 23 de dezembro). Lei № 3.858, de 23 de dezembro de 1960. Cria a Universidade de Juiz de Fora, Minas Gerais, e dá outras providências. Recuperado em 10 de novembro de 2020, de http://www.planalto.gov.br/ccivil_03/LEIS/19501969/L3858.htm

Dornelas, Roberto. (Fotógrafo). Universidade Federal de Juiz de Fora. Arquivo Central. Arquivo Permanente. Recuperada em janeiro de 2020.

ESRI (2014). Environmental Systems Research Institute. ArcGIS version 10.2.1, CD-ROM.

Geraldo, W. M. J. (2014). A reestruturação urbana pós-fordista de Juiz de Fora (Dissertação de Mestrado). Programa de PósGraduação em Geografia, Universidade Federal Fluminense, Niterói.

Google Earth. (2019). Google Earth website. Recuperado em 20 de junho de 2020, de https://earth.google.com/web/ Instituto Brasileiro de Geografia e Estatística - IBGE. (2000). Censo demográfico 2000: dados da amostra. Rio de Janeiro: IBGE. Recuperado em 10 de junho de 2020, de http://censo2000.ibge.gov.br

Instituto Brasileiro de Geografia e Estatística - IBGE. (2010). Censo demográfico 2010: dados da amostra. Rio de Janeiro: IBGE. Recuperado em 10 de junho de 2020, de http://censo2010.ibge.gov.br

Santos Júnior, G. V., Vilardi, L. O., \& Sanabio, M. T. (2019). Contratação e execução de obras públicas pela Universidade Federal de Juiz de Fora no contexto da expansão ocorrida a partir de 2007: uma análise dos possíveis fatores de insucesso relacionados à fase conceitual estratégica. In Anais do colóquio internacional de gestão universitária (p. 1-16). Florianópolis: UFSC.

Máximo, R. (2020). Efeitos territoriais de políticas educacionais: a recente expansão e interiorização do ensino federal em cidades não-metropolitanas no Ceará. urbe. Revista Brasileira de Gestão Urbana, 12 , e20190080. https://doi.org/10.1590/2175-3369.012.e20190080.

Medina, M. B. (2019). As estratégias de implantação física de universidades federais no Brasil: Um estudo comparativo entre dois períodos de expansão 1960-1970 e 2000-2010 (Dissertação de Mestrado). Programa de Pós-Graduação em Ambiente Construído, Universidade Federal de Juiz de Fora, Juiz de Fora.

Paula, K. A., \& Faria, T. C. A. (2020). Instituições Federais de Ensino Superior (IFES) e seus impactos no espaço urbano: um estudo de caso a partir da cidade de Viçosa-MG. urbe. Revista Brasileira de Gestão Urbana, 12, e20190089. https://doi.org/10.1590/2175-3369.012.e20190089

Pinheiro, C. H. L. (2018). Cidade, universidade e percepções docentes no contexto da expansão interiorizada do ensino superior público no Estado do Ceará. Revista INTERthesis, 15(2), 38-54. http://dx.doi.org/10.5007/18071384.2018v15n2p38.

Prefeitura de Juiz de Fora (2000, 27 de junho). Lei no 9811, de 27 de junho de 2000. Institui o Plano Diretor de Desenvolvimento Urbano de Juiz de Fora. Prefeitura Municipal de Juiz de Fora. Recuperado em 10 de novembro de 2020, de http://www.planodiretorparticipativo.pjf.mg.gov.br/pddu/index.htmPrefeitura de Juiz De Fora. Sistema de Informações Geográficas de Juiz de Fora. Base Cartográfica Municipal de Juiz de Fora. Secretaria de Planejamento e Gestão (SEPLAG).

Rocha, C. H. B., Pereira, B. H. C., Silva, A. F. R., Oliveira, M. de, Casquin, A. P., \& Figueireido, M. R. (2016). Impactos do uso do solo nos recursos hídricos da bacia de contribuição do Lago dos Manacás, Minas Gerais, Brasil. Revista Ambiente \& Água, 11(4), 929-94. http://dx.doi.org/10.4136/ambi-agua.1882

Rodrigues, R. A. V. (2016). Campus e cidade: uma análise dos impactos do UNIPAM no espaço urbano de Patos de Minas-MG (Dissertação de Mestrado). Universidade Federal de Uberlândia, Uberlândia.

Sanfeliu, C. B. (2011). La inserción de la Universidad en la estructura y forma urbana: el caso de la Universitat de Lleida. Revista Electrónica de Geografía y Ciencias Sociales, 15(381). 
Secretaria de Transportes e Trânsito - SETTRA. (2016, junho). Plano de mobilidade urbana de Juiz de Fora - PLANMOB-JF. Juiz de Fora: Prefeitura Municipal de Juiz de Fora.

Souza, M. de O. R. (2013). o programa MEC/BID II e o CEDATE na consolidação dos campi universitários no Brasil (Dissertação de Mestrado). Programa de Pós-Graduação em Ambiente Construído, Universidade Federal de Juiz de Fora, Juiz de Fora.

Tasca, L., \& Amaral, S. F. (2012). A Reestruturação do Espaço Urbano em Juiz de Fora a partir de Projetos Urbanos de Grande Impacto. In XII Conferência Internacional da LARES (p. 1-11). São Paulo.

Editor: Rodrigo Firmino

Recebido: 11 mar. 2020

Aprovado: 29 set. 2020 